\title{
The use of the scientific and cognitive potential of the museum of nature for forming inclusive culture in future teachers
}

\author{
Marina Grechitaeva ${ }^{1 *}$ and Marionella Kolokoltseva ${ }^{2}$ \\ ${ }^{1}$ Belgorod State National Research University, Belgorod, Russia \\ ${ }^{2}$ Astrakhan State University, Astrakhan, Russia
}

\begin{abstract}
The article analyses the innovative pedagogical technology of using the potential of natural science collections of nature museums, exposition and exhibition complexes, school mini-museums in new inclusion conditions for Russian education. The study is aimed at finding the most effective ways of forming an inclusive culture among future teachers included in exhibition activities on the basis of nature museums. Based on a synthesis of foreign and Russian experience in the formation of an inclusive culture among students, future teachers, a set of the most effective pedagogical tools, methods, techniques and forms of organization of the process under study has been determined. Specially developed diagnostic tools (criteria, indicators, levels, diagnostic methods) made it possible to analyse the experimental data obtained as a result of the application of empirical research methods: observation and interrogation. It was revealed that a common component of environmental culture, the formation of which is one of the most important areas of activity of nature museums, and inclusive culture is the formation of a valuable attitude to the diversity of the natural world and the human world. The huge educational potential of the natural science collections of nature museums, exposition and exhibition complexes, which allows students to increase their interest in studying nature, ecology, has been confirmed. The conditions of the exhibition and exhibition complexes make it possible to organize the work of groups of students, including students with disabilities, to study the objects of the world, as well as to teach excursions and quests for visitors with disabilities.
\end{abstract}

\section{Introduction}

In the modern world, an increase in the anthropogenic load on the biosphere is rampant. The global environmental crisis contributes to a person's awareness of the inadmissibility of an aggressive consumer attitude towards nature and its resources. The educational system has been given the task of educating the ecological culture of the individual, suggesting an orientation toward naturefriendly activities. Environmental education has been the subject of study by Russian and foreign scientists since the second half of the 20th century and is well developed. A feature of environmental education in the modern world is its accessibility for people with disabilities. It should be borne in mind that in the last decade, Russia has become involved in mastering the world experience of inclusive education [1]. Therefore, the task of educating a person with a high level of environmental culture is being solved in the conditions of inclusive education that are relatively new for Russia. The inclusion of children with disabilities in general education involves taking into account the specifics of this form of education, typological and individual characteristics of children with disabilities.

\section{Problem statement}

\footnotetext{
* Corresponding author: grechitaeva@bsu.edu.ru
}

Establishing the process of forming an ecological culture in the context of inclusion involves taking into account the characteristics of the interaction and communication of "special" children with healthy ones. The most important condition for providing quality education for students with disabilities is the formation of an inclusive culture in all subjects of the educational process [2]. By inclusive personality culture, we understand the totality of values that contribute to the spread of the practice of inclusive education, as well as the ability to interact, communicate with the subjects of inclusive education [3]. Thus, the research problem is as follows: what are the pedagogical means of forming an ecological culture among students with disabilities; what pedagogical means can be used in the process of forming an inclusive culture among the subjects of the educational process.

\section{Research questions}

According to our observations, both the number of insect copies and their species composition decreased in collections obtained after insecticidal treatment of hyssop fields. However, after calculating the Jacquar index for processed and untreated $H$. officinalis fields, the value was 0,7 . This points to two possible options: 1) it can be a rapid recovery of entomophilic fauna; 2) indicates resistance of certain species to insecticidal treatment. 
Both ultimately ensure that both the numbers of potential pollinators and their species diversity are preserved.

Thus, there is a contradiction between the need to form an ecological culture among students with disabilities, and the uncertainty in the choice of methods and techniques for implementing this process in an inclusive education environment; between the need to form an inclusive culture among students, including future teachers, and insufficient knowledge of the technology for implementing this process.

This contradiction proves the relevance of the stated research goal related to the search for effective means of forming an inclusive culture among future teachers. We assume that one of these tools is the natural science collections of nature museums.

The museum as a cultural and educational center is an educational environment that forms the child's understanding of the world, and the museum of nature, in particular, provides an opportunity for the development of observation abilities, systematization of information, allows laying the foundations of ecological culture, and has a powerful developing effect [4]. That is why the use of the scientific and cognitive potential of the natural science collections of nature museums in the process of inclusive education seems to be a very promising, innovative pedagogical technology [5].

Research hypothesis:

The formation of an inclusive culture among future teachers in the Museum of Nature will be successful if:

- ordinary students and students with disabilities are united through a common research, design, environmental activity on the basis of interest in studying and preserving the nature of the native land and the resources of exposition and exhibition centers, nature museums;

- the understanding of future teachers about the features of communication of people with disabilities is expanded;

- future teachers are taught how to conduct excursions and quests for visitors with disabilities.

\section{Purpose of the study}

The purpose of the study: to determine effective means, pedagogical methods and methods of forming an inclusive culture among future teachers; ways of forming an ecological culture in students with disabilities.

Research objectives:

- to study the scientific and cognitive potential of natural science collections of nature museums, methods of its use in the process of formation of environmental culture and inclusive culture among students;

- to find out what types and forms of joint activity can be organized on the basis of a museum of nature for subjects of inclusive education;

- to determine the amount of knowledge that broadens the understanding of future teachers about the features of communication of people with disabilities;

- to develop a pedagogical design of overview and thematic excursions and quests for visitors with disabilities.

\section{Methods and materials}

The study was conducted on the basis of the exposition and exhibition center "Nature of the White Mountains" Belgorod State National Research University and Astrakhan State University. The experiment was attended by 115 students of 4 courses - in the direction of preparation "Biology" and 3 courses - "Pedagogical education". When choosing diagnostic tools for determining the level of formation of inclusive culture among future teachers, we relied on the work of A. Sinyavskaya [6], V. Khitryuk [7], M. Korotkova [8]. The criteria for assessing the level of formation of an inclusive culture among students were determined: motivationalvalue; cognitive, communicative activity.

In the research process, the following empirical research methods were used: observation, survey.

To identify students' ideas about inclusive education, their attitude to this form of education, to determine the initial level of inclusive culture, we have developed a questionnaire that includes the following questions:

1) How do you feel about schoolchildren and students with disabilities studying with healthy peers?

2) Do you have experience interacting and communicating with a person with disabilities?

3) Can this experience be called positive?

4) What problems do people with disabilities face?

5) How can these problems be solved in the field of education?

6) Are you ready to interact with people with disabilities in professional activities?

7) Offer pedagogical tools for the formation of ecological culture among subjects of inclusive education in the museum environment.

\section{Results and discussion}

Quantitative and qualitative analysis of the results of the survey at an ascertaining stage of the experiment showed the following. 55 people showed a positive attitude to this form of education. (47.8\%); neutral - 51 people. (44.4\%); 9 people have a negative attitude to inclusive education. $(7.8 \%)$.

More than half of the respondents had experience interacting with people with disabilities: 64 people. $(55.7 \%)$. Of those who had such experience, it turned out to be positive - 38 people $(60 \%)$.

Students identified the following problems of people with disabilities: the difficulty of building relationships with healthy people - 62 people. (53.9\%); lack of conditions for a full life - 29 people (25.2\%); negative attitude in society towards people with disabilities - 24 people $(20.9 \%)$ (table 1$)$.

Respondents see the solution to the educational problems of people with disabilities in the following: 23 people increase the level of formation of an inclusive culture in society $(20.0 \%)$; in the education of tolerance 17 people (14.8\%); in the development of special educational programs - 16 people $(13.9 \%)$; in creating an accessible environment for people with disabilities - 13 people (11.3\%); in the use of distance learning - 15 people 
(13\%). 31 people $(27 \%)$ do not see students with disabilities in the general education system, believing that they will be better off in specialized educational institutions and on distance learning.

Table 1. Analysis of the results of a survey of students (\%)

\begin{tabular}{|c|c|c|c|}
\hline $\begin{array}{c}\text { Attitude } \\
\text { towards } \\
\text { inclusive } \\
\text { education }\end{array}$ & Positive & Undefined & Negative \\
\cline { 2 - 4 } & 47.8 & 44.4 & 7.8 \\
\hline $\begin{array}{c}\text { Problems of } \\
\text { people with } \\
\text { disabilities } \\
\text { in society }\end{array}$ & $\begin{array}{c}\text { Difficulties in } \\
\text { communication }\end{array}$ & $\begin{array}{c}\text { Lack of } \\
\text { conditions }\end{array}$ & $\begin{array}{c}\text { Negative } \\
\text { attitude }\end{array}$ \\
\cline { 2 - 4 } & 53.9 & 25.2 & 20.9 \\
\hline
\end{tabular}

To solve the identified problems, students suggest: diversify the ways of support from society - 56 people (48.7\%): to conduct joint events for healthy and "special" children - 32 people $(27.8 \%)$; educate parents of healthy children about the rights, problems and opportunities of people with disabilities - 27 people $(23.5 \%)$.

Almost half of the respondents - 56 people expressed their willingness to work to solve problems in the field of inclusive education $(48.7 \%)$. Uncertainty - 42 people (36.5\%). Unfortunately, 17 people (14.8\%) are not willing to solve the above problems in the future.

A sightseeing tour as a teaching method suitable for the formation of an inclusive culture in the museum environment was offered by 69 surveyed students $(60.0$ $\%$ ), 40 people $(34.8 \%)$ chose a thematic tour, and 6 students $(5.2 \%)$ focused on conducting quests.

Based on the data obtained, a technology was developed and tested to use the potential of nature museums to form an inclusive culture among future teachers, including:

1) the association of students with various health opportunities in research groups to study the nature and ecology of the native land in the exposition and exhibition centers and museums of nature;

2) familiarization of future teachers with the characteristics of people with disabilities

3) teaching students how to conduct sightseeing tours and quests for visitors with disabilities.

As an example, we give the scenario of the quest at the exposition and exhibition center "Nature of the White Mountains", developed by future teachers (Lysenko A.S., Dobrodomova D.E.)

Participants are divided into 2 teams. One team is given the task "Questions about the exhibition", the other - "Questions on the Red Book". Teams carry them out, then there is a change of tasks. For each team in both sections there are questions.

Questions about the exhibition:

Teams explore the exposition and exhibition center and answer questions. 1 team:

1. Which bird is located near the boars? (Gray partridge);

2. Who is watching the game flocks of birds sitting on a twig in the winter forest? (Raven)

3. Little Red Riding Hood in the winter forest (Black woodpecker);

4. What did Scarabaeus sacer set apart? (Elytra, Scarab);
5. Touchy, watching you from behind a tree (pine marten);

6. Favorite flower of a bumblebee (Clover);

7. What plant berries are sparrow and redstart eating? (Rowan);

8. A small animal in the winter forest, clutching a lump (Ordinary squirrel);

9. What is the color of the darkest flower of the Lily family? (Dark red, red);

10. What is shown on the back of the butterfly Acherontia atropos? (Skull, Dead Head);

11. Butterfly, all four wings of which look directly into the soul (Aglais io, Peacock eye);

12. Who is so surprised rook? (Hare);

13. Graceful beast with branching horns (Sika deer);

14. What large mammal is adjacent to a bird whose name will remind us of one writer? (Boar)

2 team:

1. A representative of his species is a noble astronomy lover from Smeshariki (Elk);

2. A small animal in the Winter Forest, clutching a lump (Ordinary squirrel);

3. Who didn't get along with the hedgehog? (Wolf)

4. The kid hiding behind a Christmas tree in the winter forest (Common greenfinch);

5. Primrose from monocotyledonous (Siberian sprout);

6. Bird from the winter forest with sky in plumage (Common Jay);

7. What flower name matches the injury? (Bruise);

8. Which butterfly is located on the stand differently than others (Latin name)? (Colias erate, Jaundice steppe);

9. If you take the upper north, then on which sides of the world are the wings of Tettigonia viridissima pointing? (West and South, Green Grasshopper);

10. What is the color of the eyes of a fox sitting in a corner? (Orange);

11. Which animal does not mind slowly staining its paws with dirt? (Turtle Swamp);

12. The Serpent of Gorynych has three heads, and which flying insect has three tails? (Ephialtes manifestator, Efialt-Detector);

13. The museum has a hawk, the hawk has a nest, there are chicks in the nest. How many of them? (3)

14. Not quite a tin soldier from the world of the steppes (Marmot-baibak)

\section{Red Book Questions:}

Teams work with an interactive stand on the Red Book, answer questions and enter answers in a crossword puzzle. Then, in the field highlighted in red, the name of the scientist should be obtained, about which they should tell the presenter, having studied the information on the appropriate stand.

In the third stage, the control stage of the experiment, a survey was again conducted. Students were asked to answer the same questions as at the ascertaining stage. The following results were obtained. A positive attitude towards inclusive education was revealed in 92 people $(80.0 \%)$, neutral -18 people $(15.7 \%)$, negative - in 5 people $(4.3 \%)$. Comparative results confirming the positive dynamics are presented in Fig. 1. 
As a result of the experiment, all students in the process of excursion activities gained experience in interacting with people with disabilities. Changes have also occurred in the understanding of the problems faced by people with disabilities (Fig. 2).

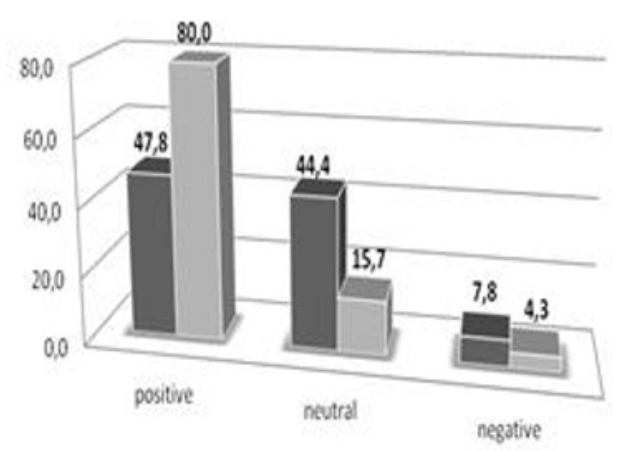

A stating experiment $\square$ A control experiment

Fig. 1. Attitude towards inclusive education (\%)

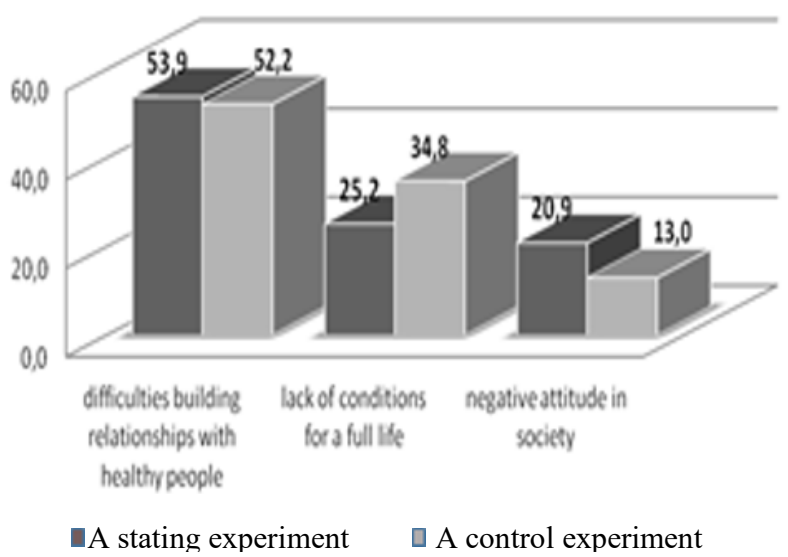

Fig. 2. Comparative analysis of understanding by future teachers of the problems of people with disabilities (\%)

Future teachers again noted the difficulties of building relationships with healthy people - 60 people $(52.2 \%)$. Although the quantitative indicator has not changed, compared with the ascertaining stage of the experiment, the students' answers have become more specific. Future teachers described the problems of people with disabilities as communicative, emotionally personal, cognitive. 40 people noted the lack of conditions for a full life in people with disabilities ( $34.8 \%$ ), which is $9.6 \%$ more than before the formation experiment. Moreover, future teachers attributed to these conditions, first of all, the lack of an accessible environment for people with disabilities. Future teachers drew attention to the fact that some sociocultural and educational institutions remain inaccessible to people with limited mobility, although in recent years there have been positive changes on this issue. A negative attitude in society towards people with disabilities was noted by 15 students $(13.0 \%$ ), which is 8 $\%$ lower than the data at the ascertaining stage.।

Future teachers proposed to solve the educational problems of people with disabilities as follows: to increase the level of inclusive culture in society - 35 people. (30.4\%); education of tolerance - 19 people (16.5 $\%$ ); development of special educational programs - 22 people (19.1\%); creating an accessible environment for people with disabilities - 15 people $(13.0 \%)$; in the use of distance learning - 14 people (12.2\%). 10 people $(8.8 \%)$ believe that it is better for some people with disabilities to study in specialized educational institutions. Comparison with data on the ascertaining stage is presented in Fig. 3.

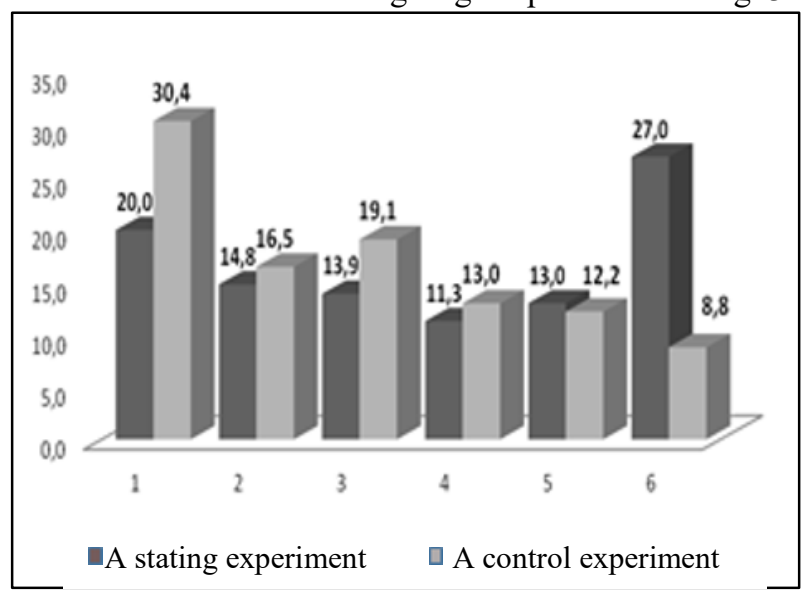

Fig. 3. Data analysis on how to solve the educational problems of people with disabilities (\%): 1 - enhancing inclusive culture in society; 2 - education of tolerance; 3 - development of special educational programs; 4 - creating an accessible environment for people with disabilities; 5 -use of distance learning; 6 -development of special educational institutions

The number of students who proposed the quest as a means of creating an inclusive culture in the museum environment increased significantly, to 83 people, which is $67.0 \%$ more than the data of the stating experiment. Data on survey and thematic excursions have not changed significantly.

\section{Conclusion}

During the study, the following conclusions were obtained:

- the huge scientific and cognitive potential of nature museums, exposition and exhibition centers, the resources of which allow students to increase their interest in studying nature, ecology, environmental protection, which is an essential component of environmental education, has been confirmed;

- the conditions of the exhibition and exhibition centers make it possible to realize group forms of organizing the educational process aimed at studying the objects of the surrounding world, presented in the form of dioramas, models of biogeocenoses, biogroups;

- conducting excursions and quests for visitors with disabilities, contributed to the students gaining vitagenic experience of interaction and communication with "special" people;

- the developed program will be useful to teachers, teachers, specialists of exhibition and exhibition centers, nature museums for organizing excursion activities aimed at fostering an inclusive culture. 


\section{Acknowledgment}

Our gratitude to the rector of Belgorod State National Research University, professor O.N. Polukhin for providing the opportunity to implement this study.

\section{References}

1. D. Sheveleva, Problems of modern education. 5, 105 (2014)

2. M. Lozovskaya, L. Belyanina, M. Kolokoltseva, N. Smirnova, International Research Journal.

Yekaterinburg. 9-5, 24 (2015)
3. M. Kolokoltseva, Pero. 70 (2019).

4. N. Makarycheva, M. Lozovskaya, in Man and Animals : Materials of the VII International Correspondence Conference. Innovative Natural Institute of Astrakhan State University. Astrakhan, Russia (2014) 